\title{
Philosophers to the Rescue? The Failed Attempt to Defend the Inclusion of Intelligent Design in Public Schools
}

\author{
Jay Sloan-Lynch
}

$\mathrm{I}^{\mathrm{n}}$ recent years, a number of philosophers have lauthored books or articles defending the teaching of Intelligent Design (ID) in public schools. For the most part, these philosophers have avoided interjecting themselves into the scientific debates concerning evolutionary theory or ID and have instead targeted what they perceive to be the flawed intellectual framework relied upon by academics in recent criticisms and judicial rulings against ID.

The general methodology employed by these philosophers is conspicuously similar. First, these critics present various arguments meant to challenge the ubiquitous tactic of rejecting the legitimacy of ID on the grounds that it isn't genuinely science. This rationale, for instance, was employed by Judge John

\section{I have yet to see a convincing argument that science, in principle, prohibits positing supernatural explanations of natural phenomena.}

E. Jones in the significant Kitzmiller v. Dover Area School District ruling that ID could not be taught in public schools because it was not properly scientific. It is argued that the presumption that biologists, philosophers, or judges possess a clear answer to the question of what is or isn't science (the "demarcation problem") is fallacious and thus attempts to exclude supernatural explanations in science $a$ priori are intellectually arbitrary.

Second, these critics argue that given the absence of clear criteria satisfactorily distinguishing evolutionary science from ID, both theories can be legitimately taught in public school science classes. While the ques- tion of how and in what context ID ought to be taught is largely eschewed, the overall conclusion held by these authors is that the teaching of Intelligent Design, perhaps even merely as "bad science" or as a suggested alternative to evolution, would not be illegitimate in the public classroom.

I am sympathetic to the claim that defining ID out of science classes by invoking contentious solutions to the demarcation problem is a fundamentally flawed approach. I have yet to see a convincing argument that science, in principle, prohibits positing supernatural explanations of natural phenomena. I will argue, however, that the move from the conclusion that ID is not nonscience to the conclusion that it is legitimate to teach it in public schools is deeply mistaken.

\section{What Is Science?}

The most common reason given for rejecting discussion of ID in science classes is based on the claim that ID violates the fundamental scientific commitment to methodological naturalism. Proper science, critics of intelligent design claim, is restricted to natural explanations of empirical evidence and confirmable data. Science, the philosopher Michael Ruse argues, "deals only with the natural, the repeatable, that which is governed by natural law." Accordingly, any explanation that references supernatural causes (e.g., an Intelligent Designer) is precluded from the proper domain of science. But what justifies defining science in such a way that keeps supernatural explanations out of the classroom?

Rarely is an argument given. Often it is simply asserted, as Ruse does, that a commitment to methodological naturalism is an essential tenet of science. The problem with this approach, as Alvin Plantinga has pointed out, is that you can't simply settle an ongoing 
dispute about what science is by citing a definition of science.

Furthermore, the belief that scientific explanations must be confined to natural phenomena ignores the existence of weighty counter-examples. For example, if the claim is that science must restrict itself simply to hypotheses that are empirically testable, then it seems possible to construct imaginative examples that involve testable supernatural explanations that could plausibly meet this criterion. Consider the following story provided by Bradley Monton:

Imagine that some astronomers discover a pulsar that is pulsing out Morse code. The message says that it's from God, and that God is causing the pulsar to pulse in this unusual way. The astronomers are initially skeptical, but they find that when they formulate questions in their head, the questions are correctly answered by the message. The astronomers bring in other people to examine this, and the questions are consistently answered. The message goes on to suggest certain experiments that scientists should perform in particle accelerators-the message says that if the experiments are set up in a specified precise way, then God will cause a miracle to occur. The experiments are done, and the resulting cloud chamber tracks spell out Biblical verses. Then the message explains to the scientists how to form a proper quantum theory of gravity...

Assuming every naturalistic explanation for the above data is exhausted, it doesn't seem unwarranted to believe that an experience like the one described by Monton would provide scientists with some testable support for the belief that God exists. Here we have empirical evidence supporting a supernatural explanation. Why simply assume, as

\section{Arguing from the premise that science ought not to be restricted solely to naturalistic hypotheses to the conclusion that we should teach non-naturalistic hypotheses in democratic schools is much too quick.}

many scientists and philosophers do, that there could never be empirical evidence for something that science cannot explain?

I have yet to hear a set of necessary and sufficient conditions adequately capturing the practice of science that is so narrow as to keep ID out but still get in everything else that would generally be regarded as legitimate science. Unfortunately, many academics and philosophers of science appear willing to give the impression of a clear answer to the demarcation problem in the public arena simply because they strongly dislike the idea of ID creeping into the science curriculum.

\section{Reliable Methods of Belief Formation}

This is not to say, however, that all approaches to reaching the truth should be taught in schools. Arguing from the premise that science ought not to be restricted solely to naturalistic hypotheses to the conclusion that we should teach non-naturalistic hypotheses in democratic schools is much too quick. Deciding what we ought to teach in democratic schools involves considerations that are importantly different from those involved in ascertaining what theoretical constraints ought to apply to the broader concept of science.

In particular, some methods of reaching belief are simply more reliable than others. It is for this reason that democratic schools should still refrain from teaching ID even if it is true that ID cannot be excluded on the grounds that it is nonscience. It is one thing to say that the concept of science should not preclude supernatural explanations by fiat, it is quite another to say that a scientific framework that allows supernatural events in addition to natural ones is an equally reliable method for reaching the truth. When considering what broad theoretical frameworks ought to guide decisions about what beliefs are taught in schools, we have copious evidence that a naturalistic framework is superior to one that appeals to miraculous or supernatural causes.

As the theoretical physicist Sean B. Carroll writes, "The preference for a natural explanation is not an $a$ priori assumption made by science; it's a conclusion of the scientific method. We know enough about the workings of the world to compare two competing bigpicture theoretical frameworks: a purely naturalistic one, versus one that incorporates some sort of supernatural component. To explain what we actually see, there's no question that the naturalistic approach is simply a more compelling fit to the observations." The scientific method is not inherently committed to naturalistic explanations, but it is committed to trying to "account for the data in the simplest and most useful way possible." And it is clear that rejecting the current naturalistic framework would introduce complicating and unnecessary elements that would violate this guiding principle.

Democratic schools should teach those beliefs most likely to be true and impart the guiding principles of scientific investigation. Teaching students a scientific framework that includes references to supernatural causes contradicts this goal; such a framework simply has not been shown to be a successful method of reaching true beliefs about reality and abandons the commitment to finding the simplest and most useful explanation for a given observation. 


\section{Failed Approaches}

On what grounds have philosophers sought to defend the inclusion of ID in public schools, following their conclusion that it cannot legitimately be considered nonscience? There are several approaches, so let us consider them individually. I will argue that none succeed in getting ID into the democratic public classroom.

In Thomas Nagel's article "Public Education and Intelligent Design," he argues that because ID and evolution both involve nonscientific presuppositions (that supernatural explanations are/are not possible), they are both in the same epistemic boat: either both are science or neither is science. The problem is that biologists simply fail to recognize "the philosophical dogma of uniformitarianism [and naturalism]" that underlies their belief in evolution and thus presume that it is only ID that involves nonscientific commitments. Evolution and ID are what Nagel refers to as "symmetrical positions," and to include one while excluding the other would result in what he believes is the irresponsible promotion of a particular worldview. The only intellectually responsible response to the fact that ID cannot be excluded on the grounds that it is unscientific is to teach ID in a "non-committal" way somewhere in the public school curriculum. Nagel, however, does not specify what he means by "noncommittal" nor does he require that ID be given equal time or even be taught in biology classrooms alongside evolution.

\section{The omission of religious ways of understanding in science classes is claimed effectively to denigrate nonsecular alternatives and endorse a naturalistic worldview.}

The philosopher Warren Nord argues in a similar vein that instruction in evolutionary theory without supplementing it with creationist views involves schools' adopting a position of religious bias and favoritism toward secularism. "A biology text that tells the story of evolution without bringing religious points of view into the discussion is taking sides. It is, in effect, saying, You don't need to understand anything about religion to understand nature." The omission of religious ways of understanding in science classes is claimed effectively to denigrate nonsecular alternatives and endorse a naturalistic worldview. This is wrong, according to Nord, because both worldviews (naturalist and religious) are essentially based on faith. And simply to choose one faith (naturalism) over another (theism) is to indoctrinate students into a particular worldview in a way that precludes the oppor- tunity to consider alternative methods of understanding. What is required, therefore, is fair and (as much as possible) neutral exposure to major nonsecular alternative positions in all science classes.

Nagel's and Nord's arguments fail to appreciate the importance of differing methods of producing belief

What would prevent proponents of ID from demanding equal time for Intelligent Design in school classrooms given that evolution and ID are held to be epistemically commensurable?

and the broader goal of democratic education. These oversights entail conclusions much stronger than I believe either wishes to defend and would portend a nightmarish standard for adjudicating what content is to be included in school curriculums.

Both Nagel and Nord refer to evolution and ID as "symmetrical positions" - that both are either science or nonscience - on the grounds that they each presuppose a set of theoretical commitments. This is true. Yet it is difficult to see how employing this standard in terms of deciding what should or shouldn't be taught in classrooms can resist the conclusion that ID should be given equal time with evolution and should be required instruction in all biology classes. What would prevent proponents of ID from demanding equal time for Intelligent Design in school classrooms given that evolution and ID are held to be epistemically commensurable?

Furthermore, accepting the argument that teaching only evolution in science classes is irresponsible because it involves endorsing certain nonscientific metaphysical assumptions about reality (i.e., that only natural explanations are permissible) opens the floodgate to the inclusion of supernatural explanations throughout the curriculum. Employing such a standard in determining what views ought to be taught would legitimate the inclusion of innumerable (and implausible) worldviews.

Given that every theory in science takes for granted various nonscientific assumptions, Nagel's and Nord's arguments would permit the inclusion of any number of supernatural and/or skeptical theories to be given equal time alongside standard scientific views. Consider a radical religious group whose hypothesis concerning the lack of sufficient mass in the universe involves invisible supernatural dumbbells used by health-conscious deities. The adherents of this group argue that from within their worldview, and given the available evidence, this hypothesis is the most reasonable explanation for the missing mass of the universe. Furthermore, they claim that it is only prejudice that 
prevents scientists from abandoning their assumption that there must be a natural explanation (dark matter, for instance) for the missing mass. Ought we to give equal time to teaching the supernatural dumbbell theory in school classrooms? This would be an outcome that even the most committed proponents of ID would like to avoid.

Simply because both evolution and ID presuppose certain theoretical commitments does not entail that their respective methods for producing true belief are equally reliable-quite the contrary. Unlike the framework of methodological naturalism in general, and evolution in particular, appeals to supernatural explanations have not been established as scientifically warranted and ID has not proven to be reliable in producing true beliefs about the origins of biological diversity. So although Nagel is correct in asserting that belief in evolution necessarily involves certain metaphysical assumptions (as all scientific theories do), experience has borne out that this method is extremely successful in producing true beliefs. This is true whether we look at the monumental successes of naturalistic science as a whole or the history of successful

\section{Evidence is simply on the side of trying to understand the world in purely natural terms and therefore this is what ought to be taught to students.}

predictions and explanations provided by evolution in particular. Evidence is simply on the side of trying to understand the world in purely natural terms and therefore this is what ought to be taught to students.

These considerations also highlight why Nord's concern with fairness and neutrality is mistaken. Democratic schools are not tasked with being fair or neutral (whatever that would mean) to all beliefs strongly held by citizens, but with imparting to children those beliefs most likely to be true and the methods employed in reaching these beliefs. In particular, those beliefs held by citizens that are inconsistent with the epistemic standards of reliability are not legitimate candidates for inclusion in democratic schools. The fact that reliable methods for producing beliefs as well as nonreliable methods both involve various theoretical assumptions is irrelevant to determining which is a superior method for generating true beliefs.

Thus I am not arguing that science classes should exclude ID on the grounds that, as Amy Gutmann has argued, "most Americans have reconciled the tenets of their faith with the findings of science" - a claim that is surely overstated. Nor am I arguing that selecting secular standards is the most fair or neutral solution.
Rather, I am suggesting that even though we find widespread acceptance in our society of both secular and religious standards, the secular standards, insofar as they meet the criteria of being epistemically reliable,

\author{
Supernatural explanations are not unscientific \\ because they appeal to nonnatural causes, but \\ because such explanations, at least at this \\ point, are superfluous.
}

are most consistent with science's guiding principles. Supernatural explanations are not unscientific because they appeal to nonnatural causes, but because such explanations, at least at this point, are superfluous and would license the inclusion of untold numbers of bizarre supernatural hypotheses in science classrooms-an outcome that should be resisted until completely necessary.

\section{Further Strategies for Inclusion}

It might be objected that this standard of reliability effectively eliminates the possibility of miracles or other one-off events being candidates for inclusion in school science classrooms. How can a miracle, which by definition is a unique event, possibly meet a standard that requires repeatability or testability? Doesn't this standard therefore inherently exclude much of religious belief? I would argue that it is mistaken to claim that the standard of reliability prohibits unique events. In fact, many scientific theories are based on one-off events- the Big Bang, the K-T extinction, etc.but even though these events are not repeatable, the general method of generating beliefs exemplified by historical science has proven to be reliable in producing true beliefs. This approach assumes that the past was like the present and then looks for a 'smoking gun' that discriminates among the available natural explanations for observed evidence. This method of generating beliefs has proven to be highly successful.

On the other hand, belief in a theoretical framework that permits the interjection of supernatural or mysterious causes has not proven to be nearly as successful in explaining the past. For example, many people believe that Mary was immaculately impregnated and experienced a virgin birth. The framework that disallows such supernatural events, however, has proven to be far more successful in explaining the causes of pregnancies than one that permits such supernatural pregnancies. Even the most convinced religious believer would be unlikely to believe a woman claiming to have been immaculately impregnated unless all natural causes were ruled out. 


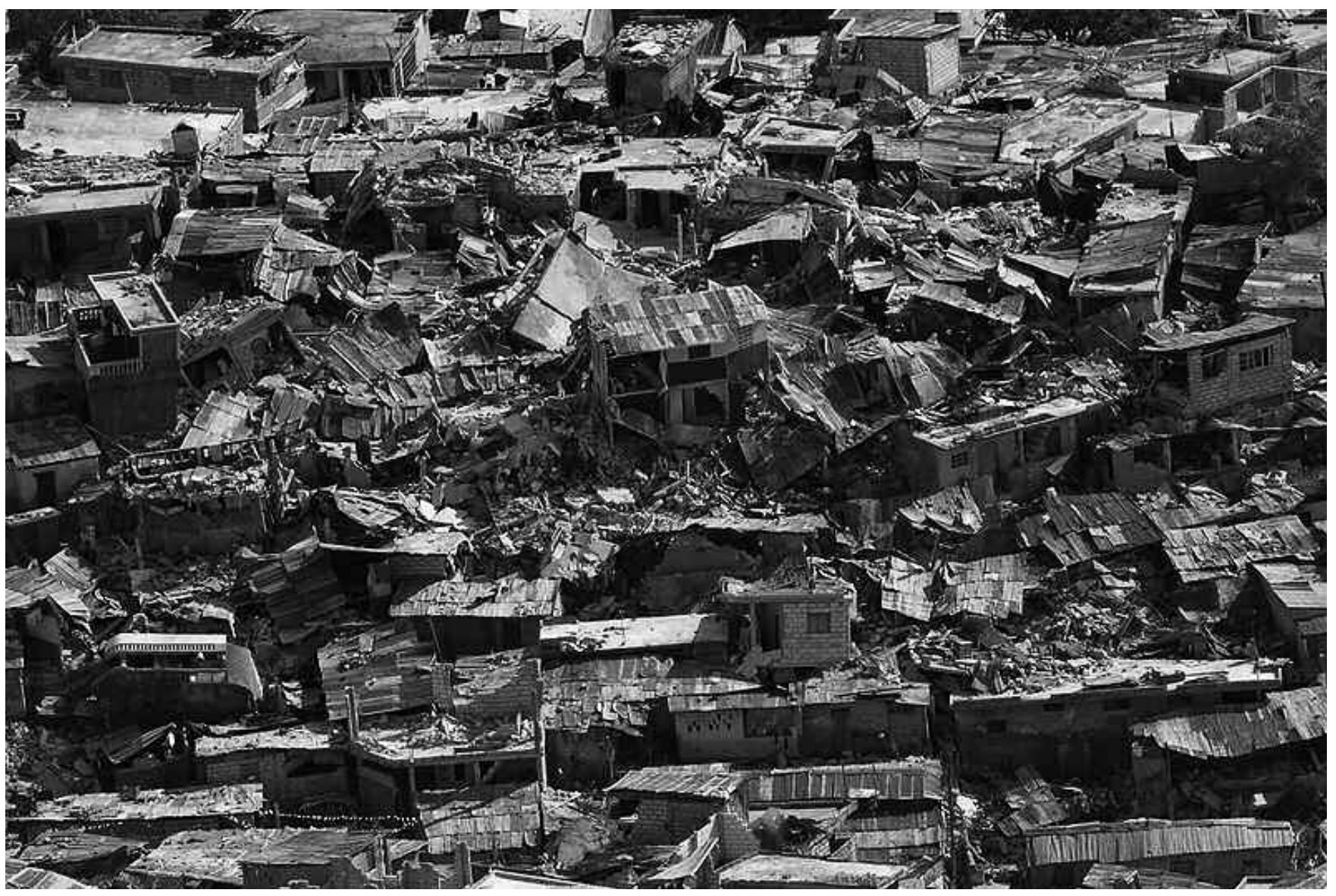

Should students be taught that the earthquake in Haiti was caused by a pact with the devil?

(UN Photo, Logan Abassi)

What other reasons might be given for including ID in public schools? Monton suggests that it may be beneficial to teach ID in public school science classes on the grounds that it might help students to learn to think more seriously about science and to contemplate scientific controversies rather than merely learning scientific content. This inquiry-based defense of ID is reminiscent of Dewey's approach to teaching science. For Dewey, teaching science should be focused on imparting an understanding of a system of experimental inquiry: not teaching the specifics of any scientific field, but the scientific method in general. Does this approach to teaching science make room for ID in public schools?

Dewey's approach to the teaching of science would certainly permit schools to forgo teaching evolution and ID altogether-focusing on the methods of science rather than teaching scientific facts and theories. Discussions about the scientific method, however, would at most give the possibility of supernatural explanations merely a passing mention given their inferior status (in terms of parsimony and explanatory power) to a naturalistic framework. Thus limiting science classes simply to scientific methodology would still justifiably exclude instruction in supernatural explanations.

What about including ID alongside evolution in order that students might engage in ongoing debates within science? It seems to me that this goal of teaching students that science is not a mere collection of

Surely it is better to exemplify good scientific methodology and actual scientific debates than needlessly use popular religious views as a scientific foil.

facts, but a dynamic and changing enterprise, should be achieved by exposing students to controversies within the naturalistic framework. Given the absence of any serious natural vs. supernatural debates in science, it would be misleading to include supernatural 
explanations of natural phenomena as legitimately debatable alternatives within science. Such debates simply do not exist.

Monton responds that students are going to hear about the theory of ID anyway. Yet the same could be said for many other supernatural explanations of observed phenomena. Should we include discussions, for instance, about both natural and supernatural causes for natural disasters because students will undoubtedly hear about this as well? Polls indicate that large numbers of religious believers think that God plays a role in creating and sending disasters to various parts of the world. Numerous religious commentators were quick to connect natural disasters like hurricane Katrina, which hit New Orleans in 2005, to divine punishment for homosexuality, legalized abortion, or overall decadence. Other examples include the 2010 earthquake in Haiti being attributed to the Haitian people swearing "a pact to the devil." Should these supernatural explanations for natural disasters be included in science classes alongside discussions of continental drift and meteorology? Surely it is better to exemplify good scientific methodology and actual scientific debates than needlessly use popular religious views simply as a scientific foil.

Would teaching ID alongside evolution be useful in promoting critical thinking? I would argue that juxtaposing the supernatural framework held by believers of ID with that of methodological naturalism would have precisely the opposite effect. Appealing to supernatural frameworks to explain natural phenomena is simply a poor standard of reasoning given current knowledge. This can be recognized in several ways: 1) even religious believers do not use this sort of reasoning in everyday life concerning issues not directly applicable to their faith; 2) this form of reasoning is not even persuasive to religious believers when confronted by dissimilar religious beliefs; and 3) it is the religious individual who is inconsistent in her standards of belief and not the nonbeliever.
Finally, Monton suggests that perhaps ID can be incorporated into science classes discussing issues pertaining to the philosophy of science. I think this is the one way in which ID can be reasonably taught in a public school science class. I see no problem with broaching the possibility of alternative investigatory frameworks that, as of yet, have not proven needed or efficacious in a philosophy of science class. Sadly, few science teachers are equipped or take the time to discuss the important and relevant issues found in the domain of philosophy of science. However, maybe if ID advocates are unable to get Intelligent Design into science classrooms any other way, they might just start trying to promote philosophy of science sections in school science curriculums. I believe this would be a good thing.

Jay Sloan-Lynch

University of Colorado at Boulder

jay.lynch@colorado.edu

Sources: Kitzmiller et al. v. Dover Area School District (400 F. Supp. 707, 2005); Michael Ruse, Darwinism Defended (Addison-Wesley, 1982); Alvin Plantinga, "Whether ID Is Science Isn't Semantics," Science and Theology News (March 7, 2006); Bradley Monton, Seeking God in Science: An Atheist Defends Intelligent Design (Broadview, 2009); Sean B. Carroll, "What Questions Can Science Answer?" Discover (July 15, 2009); Thomas Nagel, "Public Education and Intelligent Design," Philosophy E Public Affairs, vol. 26, no. 2 (2008); Warren A. Nord, Religion and American Education: Rethinking a National Dilemma (University of North Carolina Press, 1995); Amy Gutmann, Democratic Education (Princeton University Press, 1999); John Dewey, Democracy and Education (Free Press, 1997).

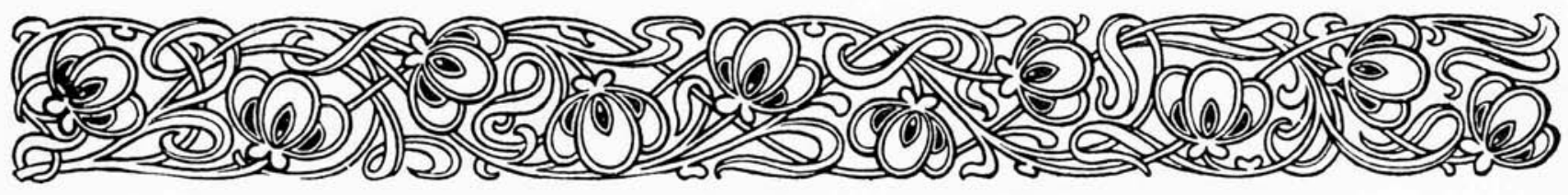


Institute for Philosophy and Public Policy

School of Public Policy

University of Maryland

College Park, MD 20742

Non-Profit Organization

U.S. Postage

PAID

Permit No. 10

College Park, MD

\section{Address Service Requested}

Established in 1976 at the University of Maryland and now part of the School of Public Policy, the Institute for Philosophy and Public Policy was founded to conduct research into the conceptual and normative questions underlying public policy formation. This research is conducted cooperatively by philosophers, policy makers and analysts, and other experts both within and outside of government.

To make its research readily available to a broad audience, the Institute for Philosophy and Public Policy publishes this quarterly journal. Articles are intended to advance philosophically-informed debate on current policy choices; the views presented are not necessarily those of the Institute or its sponsors.

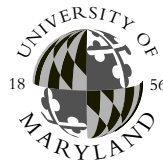

\section{The Institute for Philosophy and Public Policy}

Research Scholars:

Mark Sagoff, Director

David A. Crocker, Research Scholar

Stephen L. Elkin, Affiliated Research Scholar

William A. Galston, College Park Professor

Deborah Hellman, Affiliated Research Scholar

Daniel H. Levine, Research Scholar

Peter Levine, Affiliated Research Scholar

Xiaorong Li, Research Scholar

Judith Lichtenberg, Affiliated Research Scholar

Christopher W. Morris, Affiliated Research Scholar

Jerome M. Segal, Research Scholar

Karol E. Soltan, Affiliated Research Scholar

Robert Wachbroit, Research Scholar

Alec D. Walen, Research Scholar

David Wasserman, Affiliated Research Scholar

The Institute's Scholars constitute the Philosophy E Public Policy Quarterly Editorial Board

\section{Claudia Mills, Guest Editor}

Carroll Linkins, Program Management Specialist Barbara Cronin, Business Manager
Editorial Policy: While the principal mission of Philosophy $\mathcal{E}$ Public Policy Quarterly (ISSN 1067-2478) is to present the work of Institute members, the work of individuals who are not members of the Institute also appears in the Quarterly from time to time. Interested individuals should direct submissions to the editor. Articles that appear in the Quarterly may be made available in whole or in part to third-party indexing sources.

Correspondence with Contributors: Readers may direct their correspondence to authors, whose mailing addresses and e-mail addresses follow their articles, or in care of the editor.

Subscriptions: A subscription to Philosophy \& Public Policy Quarterly is free of charge to anyone making a request. Please let us know of changes in address, or whether you are receiving multiple copies of the Quarterly.

Electronic Access: The Institute for Philosophy and Public Policy directs interested individuals to its Web site: http://www.puaf.umd.edu/IPPP. Current and past issues of the Quarterly are available on the site. Copies of articles may be downloaded for personal use free of charge. Downloading for classroom or other use requires permission.

Permission: All materials are copyrighted by the Institute for Philosophy and Public Policy, unless otherwise acknowledged. Please direct to the editor all requests for permission to reprint articles appearing in this publication.

http://www.puaf.umd.edu/IPPP 